\title{
Factors Affecting the Implementation of Environmental Management Accounting Practices through New Institutional Sociology Perspective: A case of an Apparel Manufacturer in Sri Lanka
}

\author{
K.A.T. Nethsarani \\ University of Sri Jayewardenepura, Sri Lanka
}

D.N. Samudrage

University of Sri Jayewardenepura, Sri Lanka

\begin{abstract}
The emergence of contemporary business environment and technologies, customer driven business perspective, and transparent and accountable business practices have led different stakeholders to demand information in relation to the management of the environment. Consequently, organizations tend to develop their strategies in line with achieving these financial and environmental performances. The apparel industry is one of the significant contributors in the Sri Lankan economy and it can be seen that Environmental Management Accounting (EMA) is often practiced in this industry. However, it is a matter of consideration for the real reason behind the adoption and implementation of Environmental Management Accounting Practices (EMAPs) in this industry. Accordingly, this study is focused on identifying the actual factors that have influenced a manufacturer in the apparel industry in Sri Lanka to adopt and implement EMAPs with the perspective of the New Institutional Sociology Theory. This study takes a case study approach. Therefore, one of the leading manufacturing companies in the apparel industry was selected as the case company. The primary data were collected through a semi-structured interview and questionnaire survey. The validity of findings was assessed through data triangulation. It was identified that the environmental cost accounting, environmentally induced capital expenditure and revenue are the mostly used EMAPs whereas the payback period method is often applied in the organization for investment appraisal activities. In terms of factors that have influenced to adopt and implement EMAPs through the Institutional Theoretical Perspective, it was found that coercive isomorphism was the most significant factor whereas the least influential factor was the normative isomorphism on
\end{abstract}


the adoption and the implementation of the EMAPs in the organization. In terms of coercive isomorphism, the government regulations are the most influential force on this adoption and the implementation. Further, the study found some reasons behind the adoption of more Physical EMAPs (PEMAPs) than the Monetary EMAPs (MEMAPs) by the organization. The study contributes to minimize the gap by revealing the types of EMAPs that have been adopted and implemented and revealing the actual factors that have led to adopt and implement those practices in a manufacturer of the apparel industry.

\section{Keywords:}

Environmental Management Accounting Practices, New Institutional Sociology Perspective, Apparel Manufacturer

\section{Introduction}

Several decades ago, the managements of the organizations focused on improving firms' financial performance. They placed less importance on nonfinancial performance like environmental performance. However, with the rise of significant environmental issues like greenhouse effect, biodiversity degradation, ocean acidification, etc. people place a considerable importance on the protection of the environment than ever before. Due to this emerging pressure from the stakeholders, the organizations are much more focused on developing sustainability practices in their organizations. In this context, environmental sustainability practices came into place, to play a major role in addressing environmental impact of the operations while improving the environmental performance of the organizations. Environmental Management Accounting (EMA) is used as one of the environmental sustainability practices in the organizations and it provides the environment related information to the stakeholders.

It is argued that EMA is not a separate system; it adds value to the conventional management accounting system and provides useful information to firms to manage and improve performance and bring about sustainable development. (IFAC, 2005). In this context, EMA has become an emerging concept which is widely dispersed in various sectors in Sri Lanka. Industrial activities are some of the best instances for adopting and implementing EMAPs in Sri Lanka. The Central Bank of Sri Lanka [CBSL], (2017) indicates that the contribution from the industrial activities to the Sri Lankan economy has continuously grown for the past two decades. The growth in value addition from the contribution of industrial activities was $3.9 \%$ as of 2017 . 
Among various types of industries in Sri Lanka, the apparel industry is well known for organizations which are actively involved with the environment (Gunarathne and Alahakoon, 2016). The Board of Investments [BOI], (2019) states that the society has embraced the concept of green manufacturing which is generally known as eco-friendly manufacturing. Thus, it can clearly be seen that EMAPs are widely used in this industry (Gunarathne and Alahakoon, 2016).

EMAPs are adopted and implemented for different reasons such as pressures from various kinds of stakeholders, environmental regulations, achieving the internal efficiency etc., (Montabon et al., 2007). Hence this study is aimed at identifying the factors that have led to adopt and implement EMAPs in a case company in the apparel industry in Sri Lanka.

Since there is a gap in Sri Lankan literature regarding the factors that have led the apparel industry or the organizations to adopt and implement EMAPs with a theoretical basis, this study has analyzed the factors that have led a Sri Lankan apparel manufacturer to adopt and implement EMAPs with the perspective of Institutional Theory. Hence this study is mainly involved with three objectives; to identify Environmental Management Accounting Practices (EMAPs) followed by an organization in the Sri Lankan Apparel Industry, identify Institutional factors that lead to adopt and implement EMAPs and finally identify the types of Institutional forces that will induce EMA adoption. This study is a qualitative research study. The analysis is based on the data collected in 2019 from one of the leading companies in the Sri Lankan apparel industry via an interview and a questionnaire survey.

To identify EMAPs followed by the Apparel manufacturer in Sri Lanka, identify Institutional factors that lead to adopt and implement EMAPs and identify the types of Institutional forces that will induce EMA adoption require the study to be done in the natural setting (Yin, 2014). On the other hand, a highly detailed and a significant in-depth understanding is important for the successful achievement of the research objectives of this study (Yin,2014). Thus, the said objectives can be effectively achieved through a case study design rather than a quantitative research study. Therefore, a case study approach was applied for this study.

This study contributes a significant insight to the theoretical knowledge. Although several studies can be found in foreign literature (Jalaludin et al., 2011, Glover et al., 2014), there is a significant gap in Sri Lankan literature that has been carried out in relation to this area, specifically with a theoretical basis. Most of the studies that have been done by Peiris et al. (2014), Wickramasinghe 
(2016), Alwis et al. (2014) regarding Environmental Management Practices were focused on the hotel and tourism industry. Hence this study creates a value for Sri Lankan prior studies since the study is aimed at in-depth analysis of environmental accounting practices in relation to Sri Lankan Apparel manufacturer through Institutional Theory Perspective.

On the other hand, different industries use different types of EMAPs. There are some beliefs that EMAPs are kinds of techniques that enhance the corporate performance (Montabon et al., 2007, Nakao et al., 2007 and Klassen et al., 1996) while some use these practices as a marketing tool (Gunarathne and Alahakoon, 2016) to attract customers, suppliers and investors. Hence, in terms of practical contribution this study is particularly aimed at identifying the EMAPs adopted and implemented by the Sri Lankan Apparel sector company and the factors behind the adoption and implementation of those practices through the point of view of Institutional Theory Perspective.

The outline of this paper flows as follows. Firstly, the next section of this paper presents the literature review. The remaining sections present the empirical setting (Marble), theoretical framework and methods and data analysis. Finally, this paper explains the findings of the study and gives the conclusion.

\section{Literature Review}

\section{Environmental Management Accounting (EMA)}

Environmental Management Accounting (EMA) is defined as the management of environmental and economic performance through the development and implementation of appropriate environment related accounting systems and practices. While this may include reporting and auditing in some companies, environmental management accounting typically involves life-cycle costing, full-cost accounting, benefits assessment, and strategic planning for environmental management (IFAC, 2005).

EMA can be viewed as the identification, collection, analysis and use of physical information on the use, flows and destinies of energy, water and materials (including waste) and monetary information on environment-related costs, earnings and savings (UNDSD, 2001). Accordingly, EMA provides two types of information: Physical Environmental Management Accounting (PEMA) information and Monetary Environmental Management Accounting (MEMA). PEMA involves measuring environmental impact information expressed in terms of physical units such as kilograms of materials whereas MEMA focuses on expressing the environmental impact information in 
monetary units (Burritt et al., 2010). In fact, both physical environmental management accounting practices and monetary environmental management accounting practices are some of the essential management accounting techniques that can be used to track, trace and treat the environment related cost of the organization (Burritt et al., 2010).

One of the types of benefits of EMA is that it provides information on whether the organization has complied with relevant environmental laws and regulations applicable for the industries (IFAC, 2005). Being able to achieve eco-efficiency is another benefit of EMA (IFAC, 2005). EMA ensures the efficient use of resources and thereby would result in the reduction of both costs and environmental impacts (IFAC, 2005). Thereby EMA ensures the achievement of eco-efficiency (IFAC, 2005). For an instance, EMAPs on raw materials provides information about material analysis by the type of materials, alternatives for materials and its analysis, calculating material cost per unit, analysis of material wastage etc., to the apparel manufacturers. Thereby, the apparel manufacturers are able to control and reduce the material cost, minimize the wastage and it would result in accurate product (garments) costing. Further, EMA is beneficial in strengthening the long term strategic position of an organization (IFAC, 2005 and Solovida et al., 2017). EMA provides information which can be used to enhance the eco-friendly image of the organizations and thereby attract the environment-conscious customers, suppliers and investors (Solovida et al., 2017). For instance, EMA provides information on water management, waste management, and energy management. The apparel manufacturers can utilize this information as a marketing tool to enhance their eco-friendly image and attract customers, suppliers and invertors. Thereby, it will strengthen the strategic position of the apparel manufacturers.

With this perspective, some believed that the EMAPs should be aligned with corporate strategies to sustain the success and development of any organization (Shah et al., 2017). A company's strategy improves the environmental and economic performance (Shah et al., 2017). Hence, it is crucial taking into the consideration the Environmental performance indicators when developing a company's strategy in order to sustain the success of the company. 


\section{New Institutional Theory}

An institution is the bearer of a set of practices, a structural arrangement and configuration of rules which determines what is exemplary behavior (Olsen, 1997). Further, institutions can be defined as the social structures that have attained a higher degree of resilience. They consist of cultural-cognitive, normative, and regulative elements that, together with associated activities and resources, provide stability and meaning to social life. (Scott, 1995).

Institutional Theory can be divided into three strands (Jalaludin et al., 2011) namely, Old Institutional Economics, New Institutional Economics and New Institutional Sociology. Some of the key Institutional theorists like Meyer and Rowan (1977), DiMaggio and Powell (1983) believed that the environment in any institution highly influences the formal structure development even more than market pressures. Any innovation-based structure can be easily legitimized in an organization (DiMaggio \& Powell, 1983). However, when organizations fail to accept those innovations which have become legitimized or critical, it would be seen as or considered as the 'irrational and negligent behavior of those organizations. Therefore, organizations tend to acquire and promote a formal structural form even though it doesn't increase efficiency of the organization and for the use of legitimacy.

Institutional Theory provides essential and valuable insights into the factors that cause to change the features of organizations. In other words, Institutional Theory explains why organizational structures and practices have become more homogeneous and how and why such change occurs (DiMaggio \& Powell, 1983). Though the Institutional Theory can be divided into three strands, Old Institutional Economics, New Institutional Economics and New Institutional Sociology, this study mainly focuses on the perspective of New Institutional Sociology. New Institutional Sociology perspective explains the reasons for the adoption of homogeneous practices based on various areas such as cultural studies, cognitive science, psychology (Jalaludin et al., 2011). Further, the theory views that the organizations adopt these homogeneous practices in order to conform with the external pressures rather than to increase the internal efficiency (Jalaludin et al., 2011).

Isomorphism is one of the key concepts associated with the New Institutional Sociology Theory. According to DiMaggio and Powell (1983), isomorphism is the process through which organizations in the same line of business become homogeneous. They believed that the organizations adopt uniform structures 
due to three types of pressures/isomorphism: coercive isomorphism, mimetic isomorphism and normative isomorphism. As a consequence of formal or informal pressures that influence the organizations, coercive isomorphism occurs. For instance, pressures from government and other regulatory bodies (DiMaggio \& Powell, 1983). Mimetic isomorphism can be defined as the pressures that lead organizations to imitate successful organizational structures and practices that arise during high uncertainty (DiMaggio \& Powell, 1983). Normative isomorphism occurs due to the pressures of professionalization. In other words, similar attitudes, behaviors and practices come into the organizations with same educational backgrounds of the people (DiMaggio \& Powell, 1983). All these three pressures have individually or collectively caused organizations to adopt similar practices in the industry.

\section{Empirical Review on EMA and EMAPs}

EMA and EMAPs are widened and can be widened for a broad level of knowledge area. Thus, prior studies on EMA and EMAPs are categorized into several areas: factors affecting on the adoption and implementation of EMAPs, Institutional Theoretical Perspective on adopting and implementing EMAPs and Sri Lankan literature on EMA and EMAPs.

\section{Factors affecting on the adoption of EMAPs}

Some authors have done studies with the objective of identifying the factors that have influenced the firms to adopt EMAPs. The study carried out by Karimi et al. (2017) has contributed to this area. This study was done to modeling the factors that have influenced the financial managers who were engaged in petrochemical and oil refining companies. Hence, the study was quantitative. Further the authors have tested a population of 182 people in petrochemical and oil refining companies. And the collected data were analyzed by using both statistical and descriptive methods. Based on the results, the authors have concluded that from the perspective of financial managers in petrochemical and oil refining companies, the difficulty of collecting and allocating of environmental costs, the lack of standards, the resistance to change and culture, society and competitive environmental are the most affecting factors on adopting EMAPs in the industry. Further the authors have pointed out that there is an influence in adopting EMAPs from the experience of professional work. Hence, they have recommended that further patterns can be demonstrated for 
future studies. Hassan et al. (2011) did a study with the objective of identifying the factors that have impacted on the successful achievement of Environmental awards. The study was based on 100 FTSF UK companies and data were collected from corporate and financial reporting of the websites of those companies. It was concluded that companies are highly encouraged to achieve environmental awards to ensure that the stakeholder expectations regarding the environmental issues are met. It was found that the level of Environment related information disclosure and thereby receiving awards have been influenced by the membership in the industry and the nature of the industry sector.

\section{Institutional Theoretical Perspective on adopting and implementing EMAPs}

Relatively a few number of studies were done in relation to EMAPs with the perspective of Institutional Theory. The study done by Jalaludin et al. (2011) on understanding EMA adoption in a new Institutional Sociology Perspective is one of the significant contributions for this type of studies. The objective of the study was to identify the extent of influence from Institutional pressures on EMA adoption. The study was based on a sample of 74 accountants in Malaysian manufacturing companies. Further semi-structured interviews were done for the in-depth analysis. Based on the New Institutional Sociology Theory it was concluded that normative pressures place a significant influence on EMA adoption. Specifically, accounting body membership and training were found to be the most forceful factors out of normative pressures. The authors have emphasized that future studies can also be done with regard to EMA adoption and Institutional pressures with the involvement of other parties in an organization. On the other hand, another study was done in relation to the sustainable practices with the Institutional Theory Perspective by Glover et al. (2014). The study was qualitative and was based on the dairy supply chain in the UK. 70 Semi-structured telephone interviews were used to collect the data and constant comparison analyses were done to analyze the data. The findings highlighted that the supermarkets hold a powerful position in determining the sustainable practices across the dairy supply chain in the UK. The pressure from those supermarkets was considered as coercive pressure in the perspective of Institutional Theory. Further, the authors have emphasized the need of identifying how green sustainable practices are legitimized when competing with the purpose of reducing the cost or maximizing the profits. 


\section{Sri Lankan Studies on EMA and EMAPS}

The studies which are based on EMA and EMAPs in Sri Lankan literature have been rarely carried out. A majority of the Sri Lankan literature on EMA and EMAPs are based on the identification of EMAPs in various industries, the extent of adoption of EMAPs in Sri Lankan industries and its diffusion in Sri Lanka. A case study was done by Edirisooriya et al. (2014) with the objective of identifying the extent of EMAPs adopted and implemented by a manufacturing operation in the financial sector in Sri Lanka. The authors had collected both primary and secondary data. Hence, triangulation was used to verify the validity of data. Observing organizational processes and semi structured interviews were used as primary data collection methods whereas analyzing documents and online data were used as the secondary data collection methods. Since the study is based on the case study approach, it mainly focuses on the sale of gold. The authors have analyzed the process and identified how waste is generated and what are the treatments the management has taken to manage it. The interview with the General Manager highlighted that the top management has not paid much attention for the management of waste in the organization. Further the authors have identified that the company has achieved economic and environmental sustainability to an extent, but it lacks social sustainability. They have stated that the company has not taken reasonable actions to ensure the safety of employees who engage in the gold refining process. Hence the authors have concluded that the company is in a minimal level of social sustainability. Based on the findings, the authors have recommended that the company has to undertake the necessary health and safety measures in order to ensure the well being of society and the environment. Further, the authors have stated that the company can achieve cradle to cradle approach by use of refined grey water for the purposes like cleaning rather than release that grey water to the environment.

In contrast to the gold refining organization, another case study was done in relation to an electrical items manufacturer in Sri Lanka. The study was carried out by Thilaksiri et al. (2014) to identify how the company uses EMAPs to manage waste. The data collection methods were the same as the previous study carried out by Edirisooriya et al. (2014). Unlike the previous study, the authors have recognized that the company uses the 3 R's practices of waste management: reducing the sources, reusing and recycling. Further, the top management of the company motivates the employees to actively engage in 
waste management activities and procedures. The authors have identified that the company uses the Kaizen system, environment - oriented capital budgeting system, energy accounting as EMA tools to reduce the waste. On the other hand, the company has significantly invested in waste management projects as well. It is proven that the management has adopted and implemented the EMAPs because they have understood the hidden benefits of the use of EMAPs to the organization. The findings of this study prove that some industries in Sri Lanka are adopting and implementing EMAPs successfully. Peiris et al. (2014) also carried out a case study to examine water and waste management with the use of EMA in relation to the hotel sector in Sri Lanka. Unstructured interviews were used as the primary data collection method while informal conversations, the non - participative observation and documentary analysis were used to triangulate the data gathered in unstructured interviews. According to the findings, the selected company initially adopted and implemented EMAPs due to the guidance of the founder of the hotel. Hence, adopting and implementing EMAPs were embedded into the culture in the hotel. The findings prove that the hotel is successfully implementing the EMA system and thereby has achieved ISO 14001. According to the findings of the study, the selected hotel uses both water and waste reduction, reuse and recycle practices as EMAPs. In contrast to the two studies mentioned above, this study emphasizes that the top management has identified, that the continuous engagement of other stakeholders is vital to implement EMAPs successfully. Hence, the top management conducts staff awareness programs to train and motivate their employees in engaging water and waste management practices while using a green directory, quotes and posts to make their guests aware of sustainable practices at the hotel.

With the objective of identifying the EMAPs and its diffusion in Sri Lankan organizations, a qualitative study was carried out by Gunarathne and Alahakoon (2016). The study is mainly based on the experience on EMAPs of authors and it is specifically based on companies which are under the ownership and control of Sri Lankans. According to the study, different EMAPs are implemented by different Sri Lankan enterprises. The study covers EMAPs used in apparel, hotel, manufacturing, and plantations industries while accounting for energy, materials, water, carbon, biodiversity and life cycle costing are mainly identified as EMAPs used by those enterprises. The findings showed that there is a rapid spread of implementation of EMAPs. However, the adoption seems to be as isolated practices and it requires a high level of commitment and support from 
the top management of the organizations. The authors have stated that most of the organizations are adopting and implementing EMAPs due to various reasons such as, environmental regulatory requirements, requirements in reporting standards like GRI standards, pressures from different stakeholders etc. While organizations are adopting and implementing EMAPs for different reasons, the universities and professional accounting bodies play an active role in promoting the awareness of EMAPs in the organizations and its benefits of adopting and implementing EMAPs to the organizations as well as to the society.

While most of the studies are aiming at identifying EMAPs in different industries, some researchers carried out studies to identify the determinants of adopting and implementing EMAPs in Sri Lankan industries. Wickramasinghe (2014) carried out a quantitative study to assess the receipts of environmental awards and determinants of such receipts. The study was based on 94 hotels which were located in the Western province. Face-to-face interviews were used to gather the data and the collected data were analyzed by using Probit approach. The hotel size, chain affiliation, luxury level, classification, and number of employees per room were used as the independent variables to identify which element has an impact on determining on receiving the environmental awards and certifications. Based on the analysis of findings, the author concluded that hotels in Kalutara receive more environmental awards and certifications than the hotels in the Colombo district. Moreover, chain affiliation was recognized as the most significant determinant in receiving environmental awards and certifications for hotels. Further, the results of the study found that luxury hotels receive more environmental awards and certifications than mid range and budget level hotels. However, according to the findings the size of a hotel is irrelevant in receiving environmental awards and certifications.

\section{Methodology}

The study is based on a qualitative research study approach. Hence it explains 'how' and 'why' for a particular scenario (Yin, 2014). Thus, a qualitative research study enables to develop a deep understanding of the subject matter (Yin, 2014). In other words, it provides detailed insights into why the case organization adopts EMAPs. On the other hand, different types of research designs are available in relation to the qualitative research study approach. Out of those forms of designs, a case study approach was selected for this study for the successful achievement of the objectives in the study. According to the viewpoint of Yin (2014), a case study can be defined as an empirical inquiry 
which thoroughly investigates the contemporary scenario in a natural setting and there are unclear boundaries between the phenomenon and the context. Further, it requires a highly detailed and a significant in-depth understanding. According to Yin (2014) the case study enables thorough investigation of the present scenario. Hence, a case study approach enables to investigate the types of EMAPs adopted by the organization, the Institutional factors that lead to adopt and implement EMAPs by the organization and the types of Institutional forces that induce EMA adoption. Hence, using the case study approach for this study is more appropriate compared to other types of designs. This can be considered as one of the best strengths of the study.

This study is aimed at identifying the factors that have led to adopt and implement EMAPs in a Sri Lankan apparel manufacturer with the perspective of Institutional Theory. Thus, the nature of the study requires an in-depth analysis (Yin, 2014). On the other hand, having timely primary data increases the accuracy, validity and reliability of the conclusion of the study. By concerning all these aspects, it was decided that the qualitative case study research approach is much more suitable for this study than the quantitative research study approach.

The data was collected by using primary sources. The semi-structured interview and questionnaire survey were the main data collection methods used in the study. These two types of data collection methods were used with the purpose of data triangulation. In data triangulation, different types of methods or different types of sources are used in order to ensure the validity and reliability of data (Bryman, 2012). Thereby, with the purpose of data triangulation, an interview was conducted with an employee at management level whereas the questionnaires were distributed among the executive level employees in the finance division of Marble.

When developing the questionnaire and interview guide, firstly, the researcher analyzed the types of EMAPs by referring previous research articles. For this the study done by Jalaludin et al. (2011) on understanding EMA adoption in a New Institutional Sociology Perspective was mainly used. Based on the analysis, the most suitable EMAPs for the apparel sector organization were listed. With the objective of identifying the EMAPs which have been adopted and implemented by the apparel manufacturer, the following practices were listed out in both the questionnaire and the interview guide based on the previous literature.

- Environmental cost accounting

- Environmentally induced capital expenditure and revenue 
- Post assessment of relevant environmental costing decisions

- Environmental life cycle costing

- Environmental target costing

- Post investment of individual environmental projects

- Monetary environmental operational budgeting

- Monetary environmental capital budgeting

- Environmental long-term financial planning

- Relevant environmental costing

- Monetary environmental project investment appraisal

- Environmental life cycle budgeting

- Environmental life cycle target pricing

Further, by referring research articles on the factors that have led to adopt and implement EMAPs, the researcher prepared a list of factors. Since the study is attempting to identify those factors with the perspective of the Institutional Theory, the researcher categorized those factors into three categories: coercive factors, normative factors and mimetic factors (DiMaggio \& Powell, 1983). If Marble is adopting and implementing EMAPs due to the pressure from the powerful stakeholders, those factors were considered as the coercive factors (DiMaggio \& Powell, 1983). Finally, if Marble is adopting and implementing EMAPs or similar EMAPs with the objective of receiving competitive advantage and reducing uncertainty, those factors were considered as mimetic factors (DiMaggio \& Powell, 1983).

In the process of categorizing the factors into these three categories, the study done by Jalaludin et al. (2011) on understanding EMA adoption in a New Institutional Sociology Perspective, the study done by Hassan et al. (2011) with the objective of identifying the factors that have impacted on the successful achievement of Environmental awards, and the study done by Glover et al. (2014) in relation to the sustainable practices with the Institutional Theory Perspective were referred. Based on the lists of EMAPs and the factors under coercive, normative and mimetic factors an interview guide and a questionnaire were developed.

Before distributing the questionnaires, a pilot test was done. A pilot test helps in identifying the essentiality to modify the questions or the procedures that do not call forth the appropriate responses or enable the researchers to obtain quality data (Malmqvist et al., 2019). After making the necessary adjustments, the finalized questionnaire was distributed to two senior executive level employees in the finance division of Marble in the last two weeks of July 2019. They are 
the only employees who are accountable in dealing with sustainability issues of the organization. Hence, they were the most suitable individuals in collecting reliable and accurate data for the questionnaire survey. The developed questionnaire had three sections. Part A was based on demographic information of the respondent. It included the questions to identify the qualified respondents. In Parts $\mathrm{B}$ and $\mathrm{C}$ questions were developed on the basis of the research objectives. Part B was developed with the objective of identifying the EMAPs followed by the Apparel Manufacturer in Sri Lanka. 13 types of EMAPs were listed under Part B and it was to question the extent to which those EMAPs are used in Marble by using a Likert scale. Further, the fund allocation for EMAPs as a percentage from the total annual budget and the challenges the respondents face when implementing EMAPs in Marble were questioned. Part $\mathrm{C}$ was developed with two objectives: to identify the Institutional factors that lead to adopt and implement EMAPs and, identify the types of Institutional forces that will induce EMA adoption in Marble.

In order to gather qualitative data, an interview guide was developed. The interview guide is also a similar version of the questionnaire, but it also comprised of some open-ended questions. In other words, in addition to the data triangulation, further clarifications and explanations regarding the responses on the questionnaire survey were obtained by conducting the interview. For instance, the difference between the reporting of the bases of environmental costs, and the overall opinion on what have mostly influenced to adopt and implement EMAPs etc. In developing the interview guide the research studies carried out by Jalaludin et al. (2011), Hassan et al. (2011) and Glover et al. (2014) were referred. They were also referred in developing the said questionnaire. Further, the report prepared by Marble in accordance with the United Nation Global Compact (UNGC) principles was referred in order to obtain knowledge on the environmental management practices that are followed by Marble. An interview was conducted with an employee at management level. An interview was carried out with the environmental sustainability compliance officer who has been in the position more than five years at Marble. The environmental sustainability compliance officer is the key responsible person to adopt and implement EMAPs at the case organization. Hence, this officer is the most suitable individual for the interview in order to obtain more accurate, detailed and reliable data. Further, interviewing the other employees will not be suitable and value adding for the study, since they are not dealing with environmental sustainability concerns of the organization and are not much knowledgeable about the environmental sustainability. The interview was 
carried out in the last week of July 2019 and it lasted for more than one hour. It helped to gain an in-depth knowledge on EMAPs and clarify some processes which were mentioned in their report on UNGC principles. Further, it helped to clarify the matters regarding the data collected through questionnaires; - for instance, further clarification regarding the challenges that Marble faces when implementing the EMAPs.

For the purpose of analysis, initially, a content analysis was done in relation to analyze the information gathered through the semi-structured interview whereas the descriptive statistics were used to analyze the responses received from the questionnaire survey. Next, a comprehensive comparison was carried out between the responses received from the questionnaire survey and the interview.

\section{Case Study Company}

Since the study is based on the case study approach, one of the leading companies in the industry was selected as the unit of analysis for the study. For confidential purposes, the selected company is coded as 'Marble'. Marble is a private listed company which is one of the top apparel manufacturers in Sri Lanka. Initially the company was engaged in the manufacturing of lingerie. With the rapid growth of business over 30 years, Marble has become one of the largest teaxtile and apparel manufacturers in the South Asian region (Marble, 2017). The company manages a business portfolio along with revenue around USD 2 billion. Marble owns more than 50 manufacturing facilities which are located across more than 15 countries (Marble, 2017). Marble offers a range of products to its customers. The range includes performance wear, sports-wear, sleepwear, hoodies, T-shirts, smart clothes etc. Further, it is connected to some global clothes brands (Marble, 2017). Marble is one of the best examples for a company which is always encouraged by ethical and sustainable practices (Marble, 2017). In order to sustain suatainable manufacturing and development, Marble is actively engaged in establishing goals along with its strategy (Marble, 2017). When manufacturing garments, Marble uses recycled and sustainable materials (Marble, 2017). The work in relation to manufacturing is closely aligned with Higg index (Marble, 2017). The Higg index is a self - assessment standard introduced by sustainable apparel coalition for the apparel and footwear industry in order to assess both social and environmental sustainability throughout the supply chain (Marble, 2017). Marble has earned 59 million US\$ in revenue from this sustainable materials product range in 2017 (Marble, 2017). 
In addition to the above, with the perspective of environmental sustainability, Marble takes actions for generating renewable energy, managing footprint and supporting bio diversity (Marble, 2017). Installation of solar panels on factory rooftops is one of the instances for an action that has been taken in respect of generating renewable energy (Marble, 2017). Hence, the company represents one of the best examples for the concept of 'green garment factory' in the industry (Marble, 2017).

\section{Analysis and Discussion}

\section{Current EMAPs at Marble}

Identifying the environmental cost is very critical for an organization since it generates benefits for the organization. For instance, the customer preferences and their buying behaviors on environmental friendly products will increase the sales and profit of the organization, and show cost reduction due to being able to reduce the inefficient and wasteful consumption cost. Ultimately, these practices will lead to enhance the image of the business. Hence, for an organization tracking the environment related cost is vital as it leads to ensure its long-term survival.

EMA lies on a wide range of scope. It involves with full cost accounting, lifecycle costing, benefits assessment, and strategic planning for environmental management (IFAC, 2005). On the other hand, EMA is used in different decision making areas such as designing products, designing processes, cost allocation and cost control, capital investment etc. During the interview the environmental sustainability compliance officer commented that environmental cost accounting is one of the highly used EMAPs at Marble. He commented,

"We do environmental costing at a high level."

"Actually, we have done our best with regards to Environmental Management performances. We have traced, monitored, controlled and disclosed the information on the environment related activities. "

Environmental cost accounting attempts on tracing both accounting cost and cost benefits. In other words, it involves incorporating environmental cost information into the present accounting practices and cost allocation to the relevant products and processes (EPA, 1995). In this process Marble uses a separate software. The environmental sustainability compliance officer said that by using the software, they collect environmental data on the basis of purchase. Moreover, by using the collected data, Marble calculates the usage details on 
energy, water and waste. Responses received from the questionnaires also confirmed that environmental cost accounting is one of the key EMAPs that is used in Marble.

The report prepared by Marble according to UNGC principles also mentioned that by using the software, Marble calculates energy, waste and water usages. Further, it was said that from year 2017 onwards Marble changed from consumption based to purchase base reporting on environmental data to present more accurate data. In consumption base, the usage quantity is recorded at current market price, whereas in purchase base, the usage quantity is recorded at the historical or the actual price. Hence, the actual cost incurred from past to present, is presented in the accounts when adopting the purchasing base. The environmental sustainability compliance officer stated,

"In consumption base we usually consider the consumption amount and recorded it at the recent price. But in purchase method we record at the price of purchase date. For an example if you purchase diesel, we simply record that we have purchased this amount of diesel at this price. But in consumption method we daily record how much is consumed at the end of the day and record at the price of that day. So as you can see, the previous method was not a very accurate method."

The environmental sustainability compliance officer confirmed that environmentally induced capital expenditure and revenue is another highly used type of EMAP at Marble.

"Environmentally induced capital expenditure and revenue is highly used and post assessment of relevant environmental costing decision is used at a moderate level."

One of the other aspects he highlighted was that Marble is highly encouraged on physical environmental management accounting practices. For an instance, the environmental sustainability compliance officer said that Marble analyzes the energy consumption in different periods in a year, calculate energy intensity ratios and compare it with previous years etc. The UNGC report prepared by Marble shows a comprehensive analysis of energy, waste and water accounting practices at Marble.

However, the environmental sustainability compliance officer highlighted that, most often, they use the payback practice when assessing their projects. Investment appraisals involve inclusion of environmental costs, cost savings and revenue, emphasizing the pollution prevention on investments (EPA, 1995). 
In investment appraisals Marble includes a line item on environmental costing. Further the environmental sustainability officer commented,

"When preparing budgets, lifecycle costing and other investment appraisal projects, we include a small line on environmental costing. But we do not keep a main account or a line item".

When assessing the projects and other investments, if it cannot generate a favorable payback, then the management does not continue with the projects. Further, the officer emphasized that Marble gives priority to payback period method rather than lifecycle practice. The environmental sustainability compliance officer emphasized,

"Actually, mostly we use payback method rather than lifecycle method. Before starting any project, we do a cost benefit analysis and we include all the possible environmental impacts when doing cost benefit analysis. We only continue the project if there is a benefit for us."

On the other hand, the questionnaire survey conducted with the purpose of data triangulation also confirmed the above findings of the semi-structured interview. Two questionnaires were distributed among the senior executive level employees who are the only employees that deal with environmental issues at the finance division. Descriptive statistics were used to analyze the data and the findings of the surveys were aligned with the findings of the semi-structured interview.

The findings of the responses received from the questionnaires are shown in Figure 1. According to Figure 1, environmental cost accounting and environmentally induced capital expenditure and revenue are the highly implemented EMAPs whereas environmental lifecycle costing is the EMAP which is implemented at the lower level. 


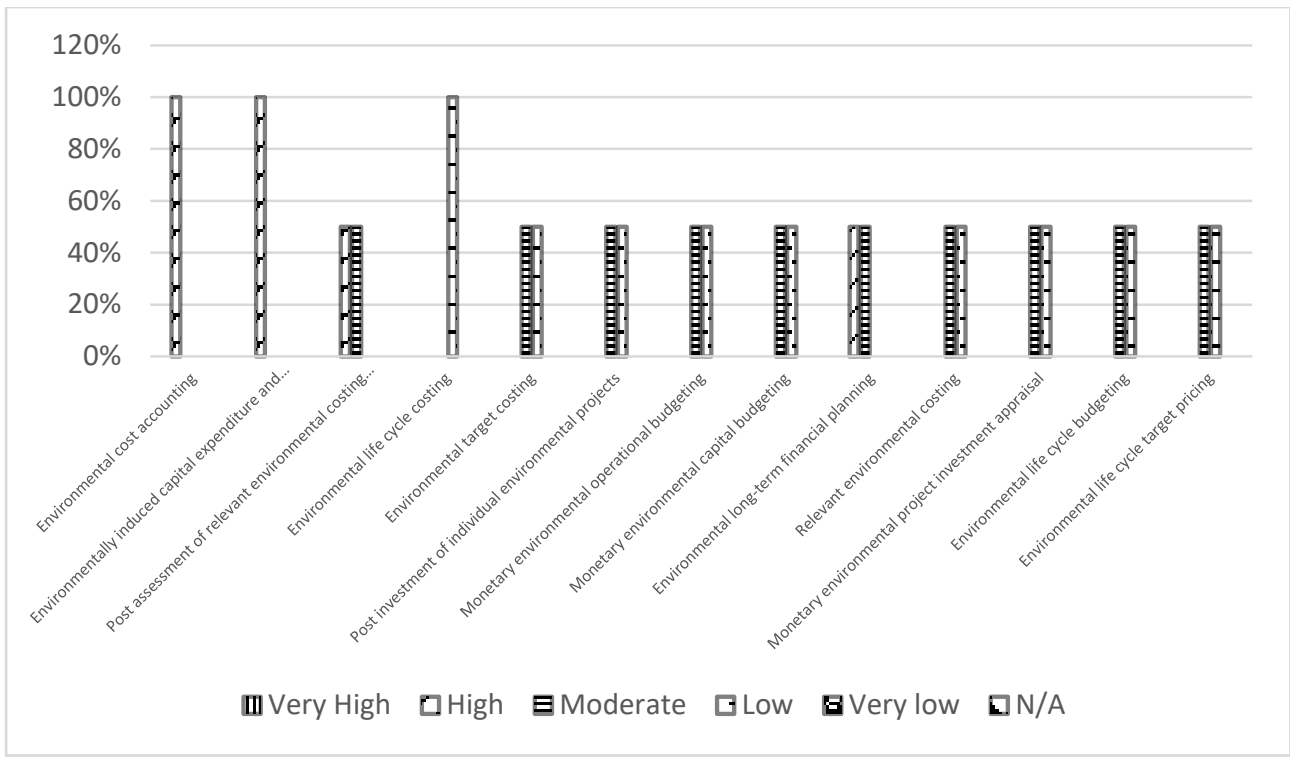

Figure 1: The level of EMAPs followed based on questionnaire survey

\section{Challenges faced when adopting and implementing EMAPs}

One of the most critical challenges is the identification of Environmental costs separately. The environmental sustainability compliance officer significantly highlighted that most of the environmental costs are hidden in the general overhead costs. The environmental sustainability compliance officer stated,

"The environmental costing is already included in overhead cost. So, we are not specifically focusing on environmental costing."

He further emphasized that it requires a lengthy process to accurately identify the environmental cost and on the other hand there can be other factors affecting in determining environmental costing. The environmental sustainability compliance officer during the interview explained, "If I give you an example, let's say we remove all the bulbs and install improved LED bulbs in the whole building. We can check the energy saving, but the value we get is for the whole building. We can say exactly how much is saved from a floor. Because there can be other factors as well. If employees from one floor work overtime, then there can be a saving. That's why we can't exactly say how much was saved from the installation. So we do post assessment, but we can't specifically identify it whether it happened due to our environmental management practices." 
On the other hand, the environmental sustainability compliance officer pointed out that the insufficient government regulations and accounting standards are some reasons for lower focus on Monetary Environmental Management Accounting Practices (MEMAPs). The instance he took was the regulations on private listed companies.

"Actually, we have done our best with regard to EMPs. We have traced, we have monitored, controlled and disclosed. The compliance is also done. We only continue the projects, if they have a payback. I think environmental accounting is already embedded into accounting. So, we don't use a separate area as EMAPs. Other than that, there are no governmental regulations on accounting practices, what they say is, we need to have management practices."

According to his explanation it is clear that as a private listed company, it is enough to report on PEMAPs through sustainability reporting. Hence, they are encouraged to make targets and achieve them through physical units rather than reporting on monetary values.

"As a private listed company, we do not necessarily need to disclose numerical figures. Even in our sustainability reporting we only reported through percentage figures and graphs etc. So, because of this we are not reporting EMAPs in monetary figures".

The use of MEMAPs would result in more accurate product costing and thereby help in deciding more accurate product pricing (Gunarathne and Alahakoon, 2016). For an instance, in the apparel sector some garments require specific dyeing processes that require careful and high cost disposals. If these costs were considered as general overhead and not as MEMA, then the costing and the pricing of the products do not reflect correctly. Hence, not only PEMAPs, but also MEAMPs are vital for management decisions.

Further, the stakeholders, especially, customers, suppliers and investors can know how much environment related cost was reduced and how much revenue was earned during the period if MEMA information is communicated to them. Thereby, they can make much more informed decisions regarding the organization.

Another fact the officer mentioned, is the comparison issues between different projects when those projects use different accounting methods. Hence, it is not an easy task to have a unique way of allocating environmental costs to the projects. 
"Other than that, the projects we are doing are different from each other. So, we can't use the same method for costing to all projects."

On the other hand, majority responses from the finance division emphasized that the cost reduction practices lead to less focus on MEMAPs.

An exploratory study carried out by Miah et al. (2015) with the objective of identifying the factors that have led to adopt environmental accounting and reporting, has also confirmed the above mentioned challenges when adopting EMAPs in relation to the Bangladeshi corporate sector. The study has revealed that the insufficient proper accounting method, issues in integrating EMA with financial accounting, comparison difficulty when using different accounting methods, insufficient provisions in the Companies Act, Securities and Exchange Commission's Act, inadequate professional guidelines on EMA and less support from Management on policies on EMAPs are some limitations when a firm is going to adopt EMAPs.

Further, during the interview, the officer stated that not only is it a challenge to implement EMAPs at Marble, but also it is a challenge to implement EMAPs in the industry. Other than the above stated reasons, the additional reason he mentioned was, the lack of proper technology to track and control environment related costs. In other words, an approved technology or software has not been developed to trace the environment related costs and the costs other than environment related costs separately in the industry. The findings of the questionnaire survey confirmed this.

"Because there is no standard or a law that encouraged or pressured us to have a separate accounting practice to account for environmental impact... Even in the GRI guidelines it doesn't say anything about EMAPs. It simply says to maintain EMPs. Another one is that the government does not focus on regulating EMAPs. Environmental law is the example. Accounting practice is not mandatory."

"Other than these, technology is not very improved to tackle the environmental cost separately. We have some issued in the case of technology."

\section{Factors for Adopting and Implementing EMAPS}

This study analyzes the factors that have led to adopt EMAPs at an apparel manufacturer with the perspective of Institutional Theory. The theory explains why organizational structures and practices have become more homogeneous and how and why such change occurs (DiMaggio \& Powell, 1983). Based on 
the New Institutional Sociology Theory, the factors are categorized into three isomorphism perspectives. They are coercive isomorphism, normative isomorphism and mimetic isomorphism (DiMaggio \& Powell, 1983).

It was considered as a coercive isomorphism factor, if Marble adopted and implemented EMAPs due to the pressures of formal and informal parties in the organization. Based on previous research literature (Jalaludin et al., 2011, Glover et al., 2014) the factors below were listed as coercive isomorphism factors.

- Government regulations

- The company's shareholders/ owners

- Newspaper and TV

- The environmental laws

- The local communities

- The company's customers

- The environmental groups

- The company's labor union

According to the environmental sustainability compliance officer there is a high influence from the government regulations, company's shareholders and customers, environmental laws and its employees.

The officer said that they are influenced by the government regulations and environmental laws. However, all those regulations and laws encourage in adopting and implementing PEMAPs, not MEMAPs.

"It has a high influence. We are influenced by the government regulations. However, we are not being pressured by the government. We do not wait until the government pressures us. But we don't have a pressure to use MEMAPs from the government. There is no law or standard to keep accounts. In environmental law, it doesn't say that we need to do EMAPs. But environmental law says to maintain the management practices. As an apparel company we have to comply with compliance laws, otherwise we can't operate in the industry."

Use of MEMAPs results in much more accurate product pricing and costing status. Hence, if the government wishes to provide certain tax reliefs in order to encourage eco-friendly manufacturing, information from MEMA will be a vital factor.

The officer further said that Marble is highly influenced by its shareholders and customers. According to his explanation the brand is a very critical and sensitive 
factor for Marble. If its shareholders and customers demand to implement a practice, then Marble takes its best action to implement those practices without any hesitation.

"We focus on stakeholders. If our shareholders want to implement or do EMAP, then we implement it. So, we have a high influence from shareholders. If customers want us to implement a practice, then we implement it. In our case, the brand is very critical to us. So, complying with relevant regulations and meeting our customers' expectation is very important to us."

Marble always appreciates the creative and innovative suggestions and opinions of its employees. Hence, there is a high influence in adopting and implementing EMAPs from its employees at Marble. The officer during the interview commented,

"Actually, in factories we have community and all employees need to be a part of that community. They gather, discuss and suggest to us to use the practices. We give priority to our employees' ideas. So, it has a high influence."

According to the opinion of the officer, Marble is moderately influenced by local communities only if the suggestion is reasonable. If that suggestion or proposal is given by the local communities who are not reasonable or do not generate a positive impact, then Marble does not implement that practice.

"It's just moderate. If it is reasonable or has a positive impact, then we do the practice. Otherwise we don't consider their requirements. If it is a reasonable one, then we obviously do the practice".

In fact, according to the Institutional Theory, most of the time, the apparel manufacturer adopts and implements similar EMAPs due to the influence of the government regulations, company's shareholders and customers, environmental laws and its employees, i.e. due to coercive isomorphism.

By analyzing the responses in the questionnaires, it can be proven that Marble is highly influenced by government regulations, company's shareholders and customers, environmental laws and its employees since all the respondents have agreed upon these factors. Figure 2 given below shows the summary of the responses received on the questionnaire survey. 


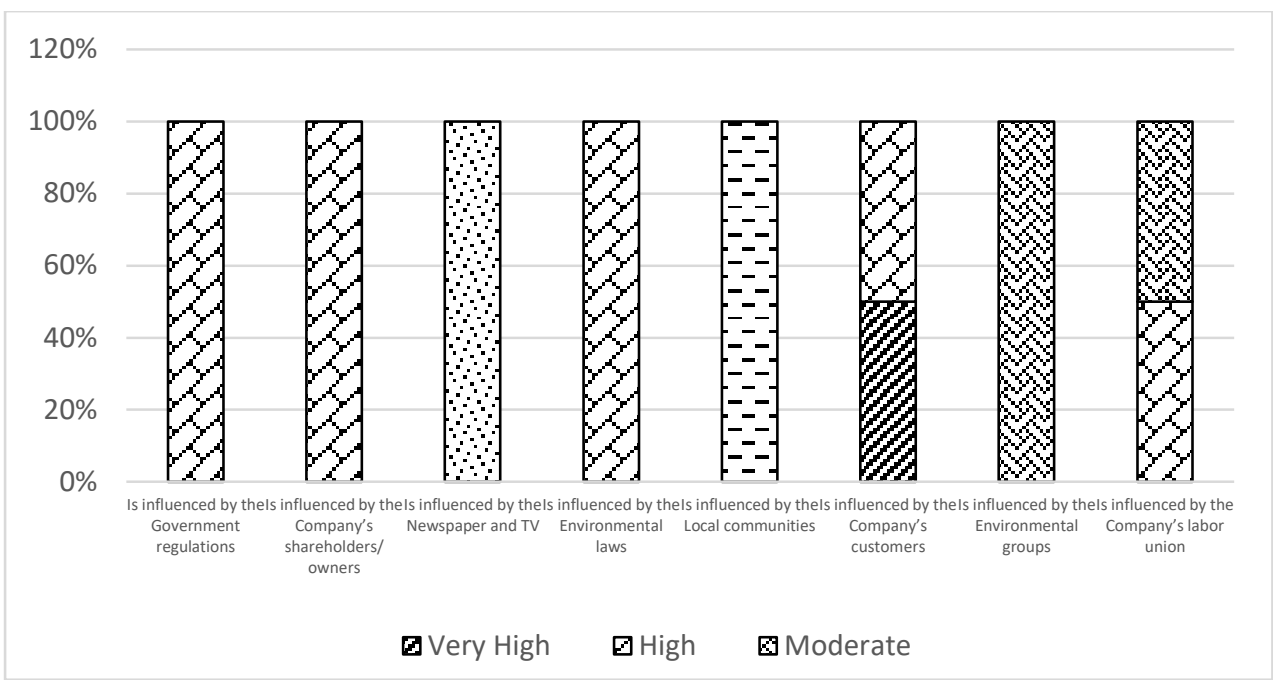

Figure 2: Analysis of coercive isomorphism that influence to adopt and implement EMAPs based on questionnaire survey

When compared to coercive isomorphism there is a very low level of influence from normative isomorphism factors. According to the Institutional Theory, normative isomorphism occurs due to the pressures of professionalization. In other words, similar attitudes, behaviors and practices come into the organizations with the same educational backgrounds of the people (DiMaggio \& Powell, 1983). After analyzing previous literature on EMAPs and Institutional Theory, the factors below were categorized as normative isomorphism factors.

- The pressure from the membership of an accounting body

- The motivation from staff training and development

According to the opinion of the environmental sustainability compliance officer, there is a very low influence and pressure from the membership of an accounting body and motivation from staff training and development.

"Accounting bodies gives the recommendations on how to account it. But it does not mean we must do the accounting part. But we do the right thing because we feel it is the right thing to do. The pressure from the accounting body is more likely to be irrelevant because there is no a specific accounting standard on MEAMPs. So, it is a very low influence. On the other hand, we do not conduct training and development mainly on MEMAPs, especially in MEMAPs. So, it is very low." 
Majority responses on the questionnaires agreed that the mentioned factors moderately influence to adopt and implement EMAPs at Marble (Figure 3).

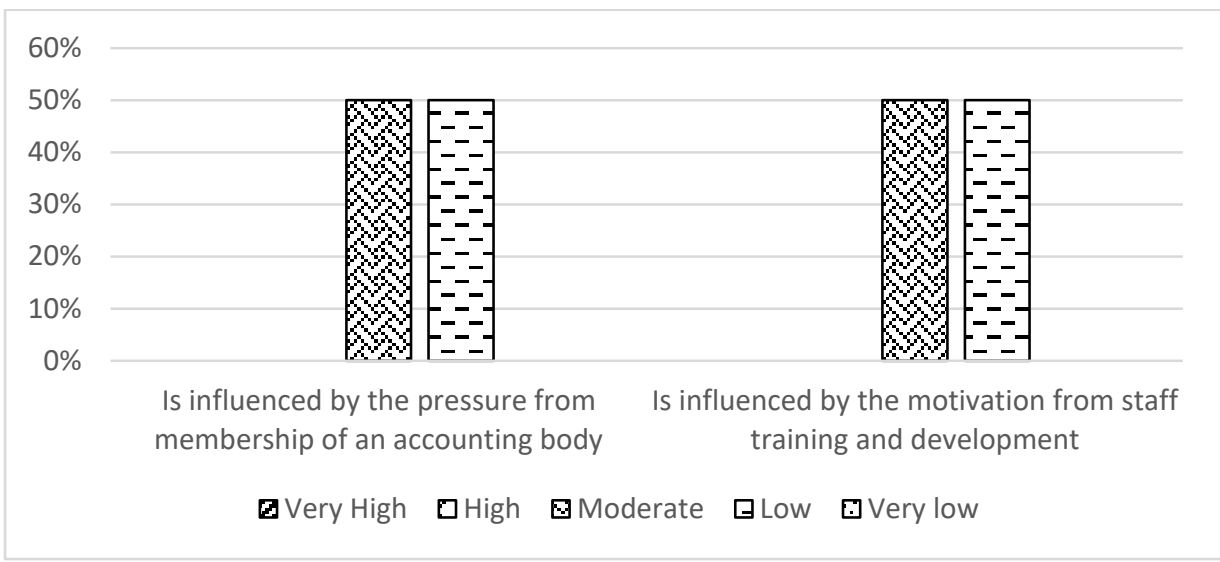

Figure 3: Analysis of normative isomorphism that influence to adopt and implement EMAPs based on questionnaire survey

Hence, based on both responses on the interview and the questionnaire, the apparel manufacturer is moderately influenced by normative isomorphism to adopt and implement similar EMAPs.

Factors were considered as mimetic isomorphism if those factors lead Marble to imitate successful organizational structures and practices that arise during high uncertainty or to obtain competitive advantage. The factors below were listed based on previous literature.

- Other leaders in the industry

- The competitors

- Other industrial organizations

- Multinational organizations

Figure 4 shows the summary of the responses of the questionnaire survey. Based on Figure 4, the majority agreed that there is a moderate level influence from all the above factors in adopting and implementing EMAPs. 


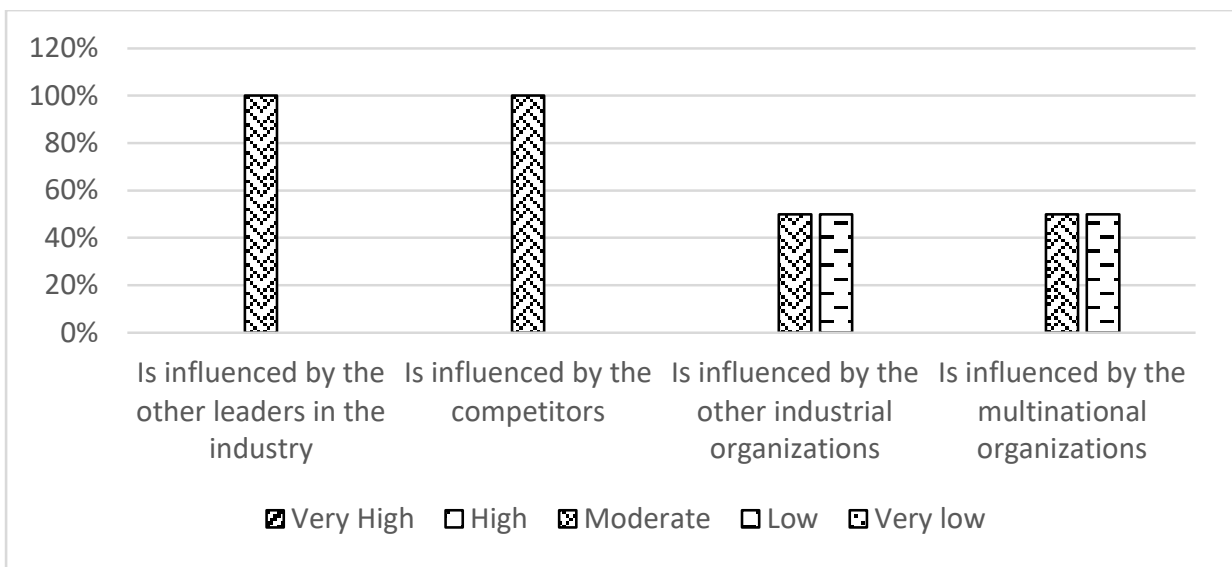

\section{Figure 4: Analysis of mimetic isomorphism that influence to adopt and implement EMAPs based on questionnaire survey}

The officer also commented,

"The influence from other leaders in the industry, the competitors, industrial organizations and multinational organizations is at moderate level in implementing EMAPs."

The opinion held by the environmental sustainability compliance officer on the first and foremost reason behind currently adopted and implemented EMAPs is environmental compliance. If Marble can't comply with relevant standards and regulations, then Marble will not be able to operate in the industry.

"The first and the main reason is environmental compliance. As I told you earlier, the apparel industry is not a good area if you consider the perspective of environment. So, you need to comply with relevant environment regulations. Otherwise you cannot operate in this industry."

The second reason according to his opinion is the industry and customer compliance. Next, he stated that influence from its shareholders and employees, is the third reason for adopting and implementing EMAPs at Marble.

"As a company we need to maintain certain standards and regulations. As you know, we are in the middle of a supply chain. If the brand says that the minimum living wage across the supply chain should be this amount, then we have to pay that wage. We give them the priority. Next, I can say is the influence from shareholders and employees. As I told you earlier, we give them priority." 
Further the officer said that, they believe that adopting and implementing EMAPs is the right thing to do.

"Finally, by doing the current practices we feel that this is a better thing to do. We give three meals to an employee. Most of the other companies do not give three meals to an employee. We do this because we feel this is the right thing to do."

By analyzing the responses in the questionnaires and the interview with the environmental sustainability compliance officer, it can be concluded that according to the Institutional Theory, the coercive isomorphism is the significant reason behind the adoption and implementation of similar EMAPs at Marble. Further, it can be concluded that the least reason in adoption and implementation of EMAPs is, normative isomorphism. The qualitative study carried out by Glover et al. (2014) in relation to the dairy supply chain with the perspective of Institutional Theory has also concluded that coercive pressures are the most significant pressure that has determined the sustainable practices across the UK dairy supply chain.

\section{Conclusion and Recommendations}

This study is based on identifying the factors that have led to adopt and implement EMAPs of a case organization in the Sri Lankan apparel sector with the perspective of New Institutional Sociology Theory. Most of the research literature is based on EMA and firm performance, barriers and challenges faced when implementing EMAPs, EMAPs in different categories such as water accounting, and EMAPs in different sectors such as the hotel industry. A very few research literature is based on the factors that have led to adopt and implement EMAPs. Further, very little literature can be found on EMAPs and Institutional Theory perspective. More specifically, most of the time, that literature is not based on the Sri Lankan apparel industry. Therefore, it is timely to conduct a research study on identifying the factors that have led the apparel industry to adopt and implement EMAPs with Institutional Theoretical Perspective.

This study was conducted with the aim of achieving three objectives; to identify EMAPs followed by the apparel manufacturer in Sri Lanka, identify Institutional factors that lead to adopt and implement EMAPs and finally identify the types of Institutional forces that will induce EMA adoption. The nature of objectives requires the study to be conducted in its natural setting. In other words, the nature of objectives requires a comprehensive and an in-depth 
investigation of the present scenario (Yin, 2014). Due to these reasons, this research study is based on a qualitative case study approach.

The first objective of the study was to identify EMAPs followed by the apparel manufacturer in Sri Lanka. The study revealed that environmental cost accounting and environmentally induced capital expenditure and revenue are the mostly used EMAPs in the organization. The second and third objectives of the study were, to identify institutional factors that lead to adopt and implement EMAPs and to identify the types of institutional forces that will induce EMA adoption. Environmental compliance rules and regulations, industry and customer compliance, shareholder and customer compliance were the reasons behind the determination of factors that have led to adopt EMAPs. Since these factors come under the coercive factors, it was concluded that coercive isomorphism is significant in the decision of adopting and implementing EMAPs in the organization. Further, the study found that normative isomorphism factors influence at a low level in the adoption and implementation of EMAPs. Lack of proper standards in environmental standards, insufficient provision of guidelines by the accounting bodies were the key reasons behind this lower level influence in adopting and implementing EMAPs. However, all these reasons are related to MEMAPs. MEMAPs are not mandatory standards or guideline like GRI guidelines. In other words, according to the sustainability report (2019) issued by the Colombo Stock Exchange (CSE), it is not a mandatory requirement to present details of MEMAPs, even though it is recommended to communicate environmental information to the stakeholders. If MEMA information is communicated to the stakeholders, they can make much more informed decisions regarding the organization. For instance, revenue generated from eco-friendly manufacturing and materials and environment related cost reduction information will provide valuable insights to their decisions regarding the organizations.

In addition to the above findings, the study has also recognized some barriers and challenges faced by the industry when adopting and implementing EMAPs. Identifying the environmental costs and expenses, capitalizing those expenses, identifying the environmental liabilities and measuring those liabilities are some problems encountered by the company. Currently, there is a lack of proper accounting standards being issued in Sri Lanka. However, it can be recognized that some advisory guidelines were issued by the Financial Accounting Standards Board (FASB), Accounting Advisory Forum (AAF), Institute of Chartered Accountants of England and Wales etc. 
Further, in Sri Lanka it is not a mandatory requirement to report on financial and non-financial environmental performance data. However, the Securities Commission in Canada requires the companies to report both present and future operational and/or financial effects of environmental protection requirements. Though EMA is essential in product pricing, costing, budgeting, cost savings and investment appraisals (EPA, 1995), the findings of the study emphasized that it is not easy to separately identify the environmental costs and it is already hidden in the overhead cost. This problem can be solved by considering the solutions suggested by the United Nations Division for Sustainable Development (UNDSD, 2003).

UNDSD (2003) suggested that flow cost accounting, input/output analysis, activity-based costing and life-cycle costing as some management accounting techniques that can be used to identify and allocate the environmental costs. The volume of emissions or waste, toxicity of emission and waste treated, environmental impact added, volume of the emissions treated, can be taken into consideration in determining the cost allocation keys. Further increasing the awareness of the benefits of EMA and the effective and efficient use of both MEMAPs and PEMAPs is another essential recommendation to the successful implementation of EMAPs, for instance, convincing the organizations on how MEMA information would result in accurate product costing pricing.

It is highly recommended to make both MEMA and PEMA as mandatory reporting requirements in Sri Lanka. Another recommendation is the developing of the conceptual framework or an accounting standard by the accounting bodies with the emphasis on objectives, assumptions and mandatory guidelines to encourage both MEMAPs and MEMAPs. Also, it is recommended to develop organizational policies on both MEMAPs and PEMAPs. Since there is an unavailability of mandatory reporting rules and regulations, by initiating company specific EMA policies will result in developing the image of the organization and gaining the competitive advantage. In developing the policies, a company can take into the consideration the guidelines that are already established by the above-mentioned organizations such as CICA.

The Sri Lankan apparel sector is a significant contributor to the economy. Out of the large population, only one company was selected to collect data. Hence, the scope is limited and it is difficult to generalize the findings to the entire population. Though the study has some inherent drawbacks, it has contributed an in-depth knowledge and information in relation to the theory and practice. In the perspective of theoretical contribution, this study has attempted in analyzing the factors that have led to adopt and implement EMAPs through the 
Institutional Theoretical Perspective. Moreover, the findings of the study have unveiled how the theoretical EMAPs are practically used in the apparel company. In the perspective of practical contribution, this study has unveiled the actual reasons behind the adoption and implementation of EMAPs in the apparel manufacturer in Sri Lanka. Further, the study has revealed the types of EMAPs that are being implemented in the apparel manufacturer in the industry. Another practical contribution of this study is the exposing of the barriers and challenges encountered by the organization in the apparel industry.

Though the study has made a significant contribution to the theory and practice, further research studies can be carried out in different industries. On the other hand, further studies can be conducted on how the recommendations of the study were used to mitigate the challenges and barriers faced by the industry regarding the adopting and implementation of EMAPs. Since EMA and EMAPs lie on the broadened scope, this study can also be conducted in other sectors in Sri Lanka. For instance, further studies can be conducted to identify the factors that have led to adopt and implement EMAPs in the Sri Lankan construction industry.

\section{Declaration of Conflicting Interests}

The authors declared no potential conflicts of interest with respect to the research, authorship, and publication of this article.

\section{References}

Alwis, K. U. I., Arachchige, V. K. A. S. W. K., Seneviratne, P. M., Thiruvalluvar, G., \& Weerarathne, H. M. S. V. (2014). Solid waste and waste water management in the Hotel sector: Empirical Evidence from a Sri Lankan case. Journal of Accounting Panorama, 1, 46-68.

An introduction to Environmental Accounting as a Business Management tool: Key concepts and terms . (1995). Office of pollution prevention and toxics, Washington: US Environmental Protection Agency (EPA). Retrieved from https://www.epa.gov/sites/production/files/2014-01/documents/busmgt.pdf Andrew, A. K., \& Michael, J. L. (2001). Does it really pay to be green? An Empirical study of firm environmental and financial performance. Journal of Industrial Ecology, 5, 105-116. doi:10.1162/108819801753358526

Board of Investments (BOI). (2019). Apparel Web. Retrieved January 02, 2019, from http://investsrilanka.com/sectors/apparel-2/

Bryman, A. (2012). Social research methods. New York: Oxford University Press. 
Burritt, R. L., \& Schaltegger, S. (2010). Sustainability accounting and reporting: fad or trend? Accounting, Auditing \& Accountability Journal, 23(7), 829-846.

Central bank of Sri Lanka (CBSL). (2017). Annual Report 2017. Retrieved February 2, 2019, from https://www.cbsl.gov.lk/en/publications/economicand-financial-reports/annual-reports/annual-report-2017

Colombo Stock Exchange (CSE). (2019). Communicating Sustainability, Six recommendations for listed companies. Retrieved August 2, 2019, from https://cdn.cse.lk/pdf/sustainability-document.pdf

DiMaggio, P., \& Powell, W. (1983). The Iron Cage Revisited: Institutional Isomorphism and Collective Rationality in Organizational Fields. American Sociological Review, 48(2), 147-160. doi:10.2307/2095101

Edirisooriya, K. K., Noopehuwa, P. U., Perera, S. A., \& Silva, M. N. (2014). Environmental Management Accounting in a manufacturing arm of financial sector organization: A case of a Sri Lankan organization. Journal of Industrial Ecology, 1, 69-84.

Glover, J. L., Champion , D., Daniels, K. J., \& Dainty, A. J. (2014). An Industrial Theory perspective on sustainable practices across the dairy supply chain. International Journal of Production Economics, 152, 102-111.

Gunarathne, A. D., \& Alahakoon, Y. (2016). Environmental Management Accounting Practices and their Diffusion: The Sri Lankan Experience. NSMB Journal of Management, 2(1), 1-26.

Hassan, A., \& Ibrahim, E. (2011). Corporate Environmental Information Disclosure: Factors influencing companies' success attaining. Corporate Social Responsibility and Environmental Management, 19(1), 32-46.

Heenetigala, K. (2011). Corporate governance practices and firm performance of listed companies in Sri Lanka. Retrieved April 27, 2019, from http://vuir.vu.edu.au/16050/1/Kumudini_Heenetigala_thesis.pdf

International Federation of Accountants (IFAC). (2005). International Guidance Document: Environmental Management Accounting. New York: IFAC.

Jalaludin, D., Sulaiman, M., \& Ahmad, N. N. (2011). Understanding environmental management accounting (EMA) adoption: a new institutional sociology perspective. Social Responsibility Journal, 7(4), 540-557.

Jasch, C. (2003). The use of Environmental Management Accouting (EMA) for identifying environmental costs. Journal of cleaner production, 11(6), 667676. doi:10.1016/S0959-6526(02)00107-5

Karimi, Z., Dastgir, M., \& Saleh, M. A. (2017). Analysis of factors affecting the adoption and use of Anvironmental Management Accounting to provide a 
Conceptual model. International Journal of Economics and Financial Issues, 7(3), 555-560.

Klassen, R. D., \& McLaughlin, C. P. (1996). The impact of Environmental Management on firm performance. Management Science, 42(8), 1199-1214.

Magablih, A. M. (2017). The impact of Green Accounting for reducing the environmental cost in production companies. Journal of Modern Accounting and Auditing, 13(6), 249-265. doi:10.17265/1548-6583/2017.06.002

Malmqvist, J., Hellberg, K., Mollas, G., Rose, R., \& Shevlin, M. (2019). Conducting the Pilot Study: A Neglected Part of the Research Process? Methodological Findings Supporting the Importance of Piloting in Qualitative Research Studies. International Journal of Qualitative Methods , 18, 1-11. doi: $10.1177 / 1609406919878341$

Marble (Pvt) Ltd. (2017). Communication on progress 2017. Retrieved July 2, 2019, from https://s3-us-west-2.amazonaws.com/ungcproduction/attachments/cop_2018/465070/original/MAS_HOLDINGS_COP_ 2017.pdf?1530341720

Meyer, J. W. (1977). Institutionalized Organizations: Formal Structure as Myth and Ceremony. The American Journal of Sociology, 340-363.

Miah, M. S., Islam, M. S., \& Fakir, A. N. M. A. (2015). Environmental Accounting and Reporting-An Analysis of Bangladeshi Corporate Sector . Journal of International Business Studies.

Montabon, F., Sroufe, R., \& Narasimhan, R. (2007). An examination of corporate reporting, environmental management practices and firm performance. Journal of Operations Management, 25(5), 998-1014.

Muhammad, N., Scrimgeour, F., Reddy, K., \& Abidin, S. (2015). The realationship between environmental performance and financial performance in periods of growth anf contraction: Evidence from Australian publicly listed companies. Journal of cleaner production, 102, 324-332. doi:10.1016/j.jclepro.2015.04.039.

Nakao, Y., Amano, A., Matsumura, K., \& Nakano, M. (2007). Relationship between environmental performance and financial performance: an empirical analysis of Japanese corporations. Business Strategy and the Environment, 16(2), 106-118.

Noodezh, H. R., \& Moghimi, S. (2015). Environmental costs and environmental information disclosure in the accounting systems. International Journal of Academic Research in Accounting, Finance and Management Sciences, 5(1), 13-18. 
Olsen, J. P. (1997). Institutional Design in Democratic Contexts. The Journal of political philosophy, 5(3), 203-229. doi:10.1111/1467-9760.00032

Peiris, T. S., Dissanayake, D. M., Herath, N. T., \& Thanthree, P. K. (2014). Managing waste and water with the help of Environmental Management Accounting (EMA): A Sri Lankan hotel sector case. Journal of Accounting Panorama, 1, 12-28.

Qian, W., Burritt, R., \& Monroe, G. (2011). Environmental Management Accounting in local government: A case of waste management. Accounting, Auditing and Accountability Journal, 24(1), 93-128. doi:10.1108/09513571111098072

Scott, W. R. (1995). Institutions and Organizations. Ideas, Interests and Identities. 2(2), 136-140. doi:10.3917/mana.172.0136

Shah, S., Ganji, E. N., \& Hasan, S. (2017). An analysis of Environmental Management and Sustainability in SMEs. WSEAS Transactions on Business and Economics, 13(16), 137-149.

Solovida, G. T., \& Latan, H. (2017). Linking environmental strategy to environmental performance: Mediation role of Environmental Management Accounting. Sustainability Accounting, Management and Policy Journal, 8(5), 595-619.

Srouf, R., Montabon, F., Wang, X., \& Narasimhan, R. (2002). Environmental management practices: A framework. Greener Management International, 40(1), 23-44. Retrieved April 18, 2019, from https://lib.dr.iastate.edu/cgi/viewcontent.cgi?article=1032\&context=scm_pubs

Thilaksiri, N., Kurukulasooriya, S., De Silva, Y., \& Dias, D. (2014). Integrating Environmental Management Accounting (EMA) practices with waste management: A case of electrical item manufacturer in Sri Lanka. Journal of Accounting Panorama, 1, 85-101.

Tissera, M., Samarakoon, D., \& Senanayake, G. (2017). Linking tourism, energy and agriculture through sustainable consumption and production in Sri Lanka. In Sustainable Asia (pp. 267-290). World Scientific Publishing Company. doi:10.1142/9789814730914_0011

Tsui, C. S. K. (2014). A literature review on Environmental Management Accounting (EMA) adoption. Web Journal of Chinese management review, 17(3). Retrieved August 10, 2019, from http://cmr.ba.ouhk.edu.hk/cmr/webjournal/v17n3/CMR439E13.pdf

United Nations Division for Sustainable Development (UNDSD). (2003). Environmental Management Accounting Procedures and Principles. Environmental Management Accounting Research and Information Center. 
Van, H. (2012). Environmental Accounting - A new challenge for the Accounting system,Public finance Quarterly. Public Finance Quarterly, 57(4), 437-452. Retrieved July 27, 2019, from https://pdfs.semanticscholar.org/c5f1/22e7dec5b22db71443b1a3aa485ef9a53a ae.pdf

Wickramasinghe, K. (2014). Determinants of receipts of environmental awards and certifications by hotels: experience from the Western province in Sri Lanka. Journal of Environmental Professinals Sri Lanka, 3(2), 41-47.

Wickramasinghe, K. (2016). Adoption of Environmental management practices in the hotel industry in Sri Lanaka,Working paper. (pp. 114-116). Kathmandu: South Asian Network for Development and Environmental Economics (SANDEE). $\quad$ Retrieved March 17, 2019, from http://www.sandeeonline.org/uploads/documents/publication/1098_PUB_Wor king_Paper_No._114-16.pdf

Wilmshurt, T. D., \& Frost, G. R. (2000). Corporate environmental reporting: A test of legitimacy theory. Accounting,Auditing and Accountability Journal, 13(1), 10-26. doi:10.1108/09513570010316126

Yin, R. K. (2014). Case study research: design and methods (5th ed ed.). Sage, Thousand Oaks, CA.

Zhengang, Z., Weerasiri, R. A., \& Dissanayake, D. M. (2012). Attitudes, awareness and environmental management practices of small and medium sized enterprises (SMEs) in Sri Lanka. Journal of Social and Development Sciences, 3. doi:10.22610/jsds.v3i1.681. 